\section{The effect of lockdown on the COVID-19 epidemic in Brazil: evidence from an interrupted time series design}

\author{
O efeito do lockdown sobre a epidemia da COVID-19 \\ no Brasil: evidências a partir de uma análise de \\ séries temporais interrompidas
}

El efecto del confinamiento por la epidemia de COVID-19 en Brasil: evidencia de un diseño de serie temporal interrumpida
Lucas Silva 1,2

Dalson Figueiredo Filho 1

Antônio Fernandes 1

doi: 10.1590/0102-311X00213920

\begin{abstract}
In response to the COVID-19 pandemic, governments worldwide have implemented social distancing policies with different levels of both enforcement and compliance. We conducted an interrupted time series analysis to estimate the impact of lockdowns on reducing the number of cases and deaths due to COVID-19 in Brazil. Official daily data was collected for four city capitals before and after their respective policies interventions based on a 14 days observation window. We estimated a segmented linear regression to evaluate the effectiveness of lockdown measures on COVID-19 incidence and mortality. The initial number of new cases and new deaths had a positive trend prior to policy change. After lockdown, a statistically significant decrease in new confirmed cases was found in all state capitals. We also found evidence that lockdown measures were likely to reverse the trend of new daily deaths due to COVID-19. In São Luis, we observed a reduction of $37.85 \%$ while in Fortaleza the decrease was $33.4 \%$ on the average difference in daily death if the lockdown had not been implemented. Similarly, the intervention diminished mortality in Recife by $21.76 \%$ and Belém by $16.77 \%$. Social distancing policies can be useful tools in flattening the epidemic curve.
\end{abstract}

SARS-CoV-2; COVID-19; Social Distance; Interrupted Time Series

\section{Silva}

Rua Dr. Jorge de Lima 113, Maceió, AL 57010-300, Brasil. lucas.silva@academico.uncisal.edu.br

1 Universidade Estadual de Ciências da Saúde de Alagoas, Maceió, Brasil.

2 Universidade Federal de Pernambuco, Recife, Brasil. 


\section{Introduction}

The first confirmed case of SARS-CoV-2 in Brazil was identified on February 26th 2020 (Ministério da Saúde. https://covid.saude.gov.br/, accessed on Jul/2020). Since then, Brazil became the second most affected country worldwide with 1,884,967 diagnosed cases, and has the second-highest number of total deaths due to COVID-19, with 72,833 fatalities as of July 13th (Ministério da Saúde. https:// covid.saude.gov.br/, acessado em Jul/2020). While SARS-CoV-2 spread over space and time, Brazilian President Jair Bolsonaro repeatedly advocated that COVID-19 was not more dangerous than a regular flu 1 and that strict quarantine measures were worse than the disease itself due to its adverse economic net effects 2 .

Contrary to the president's stance, some State Governors adopted lockdown policies trying to prevent the spread of the SARS-CoV-2 pandemic, with specific measures restricting social contact being first introduced in the Northern and Northeast regions. On May 5th, the State of Maranhão, in the Northeast Region, implemented strict regulations imposing social distancing. After this experience, other state governors and city mayors also adopted more stringent social distancing measures. A heated debate accompanied the implementation of hard, statewide lockdowns in several locations on how much they could achieve, how much they would cost, and how long they should last 3 . As some of the states undergoing lockdown measures have announced in June their decision to lift restrictions and resume normalcy progressively, careful analysis is required to assess the effectiveness of such policies.

In this paper, we conducted an interrupted time series (ITS) analysis to estimate the impact of social distance measures on reducing both the number of cases and deaths due to COVID-19 in Brazil. The selected sample included all the Brazilian state capitals that officially adopted more restrictive policies (i.e. "lockdown") in response to the SARS-CoV-2 epidemic: Belém (Pará State), Fortaleza (Ceará State), Recife (Pernambuco State), and São Luís (Maranhão State).

\section{Materials and methods}

\section{Data collection}

On June 25th, we collected data from the Brazilian Ministry of Health website, which provides daily disaggregated information on COVID-19 (https://covid.saude.gov.br/), and later identified the time frame for lockdown measures in each city (Table 1). Following previous literature on the effects of lockdown measures on the COVID-19 pandemic, we adopted a two-week observation window after the end lockdown policies to test the series interruption 4,5,6,7.

The adoption of 14 days corresponds to the disease incubation period as reported by the World Health Organization (WHO) 8 and medical empirical research 9,10,11. Thus, we expected to observe a delayed policy effect. For instance, a person who becomes infected on the last day of public intervention may experience symptoms up to 14 days after the end of the policy change.

After data cleaning and coding, we analyzed the trends reported daily in each city before and after their policy change focusing on two primary outcomes: daily new cases and deaths. We specified an ordinary least squares regression model using the logarithmic transformation on the dependent variables.

Table 1

Lockdown information for Brazilian capitals.

\begin{tabular}{lcccc}
\hline City (State) & Population & Lockdown period & Lockdown duration (days) & Post-intervention window \\
\hline São Luís (Maranhão State) & $1,101,884$ & May 5th to May 17th & 13 & Until May 31 \\
Recife (Pernambuco State) & $1,645,727$ & May 16th to May 31st & 16 & Until June 14 \\
Belém (Pará State) & $1,492,745$ & May 7th to May 24th & 18 & Until June 7 \\
Fortaleza (Ceará State) & $2,669,342$ & May 8th to May 30th & 23 & Until June 13 \\
\hline
\end{tabular}




\section{Statistical analysis}

ITS design is the most reliable quasi-experimental approach for evaluating the effects of discrete interventions on longitudinal data 12. Technically, ITS is flexible, comfortably accommodating both continuous and discrete outcomes measured at regularly spaced intervals 13 . Another vital feature of the ITS is its intuitive graphical display. Visually, we compare the distribution of an outcome variable over time before and after the intervention 14,15. The higher the difference between the observed series and what should have happened, the more significant the intervention's impact. We assumed that the level (average) and the trend of the series would remain constant in the absence of government policy (intervention) 16,17. The statistical model was specified as follows:

$$
Y_{t}=\alpha+\beta_{1} X_{1}+\beta_{2} X_{2}+\beta_{3} X_{3}+\varepsilon
$$

Where $Y_{1}$ represents the number of daily new cases/deaths, $X_{1}$ is a discrete variable indicating the pre-intervention trend, $X_{2}$ is a dummy variable representing the level change immediately after policy intervention ( 0 = before lockdown, 1 = after lockdown), and $X_{3}$ indicates the slope change following the lockdown which is calculated as a multiplicative term between $X_{1}$ (time) and $X_{2}$ (level).

We expected a positive trend before the intervention, e.g., $\beta_{1}>0$. Assuming a 14-day incubation period, we considered that $\beta_{2}$ should be positive, regardless of statistical significance. Thus, no immediate trend changes after intervention was expected. Following Bernal et al. 13, we expected to observe a negative trend of cases and deaths after the policy change $\left(\beta_{3}>0\right)$.

Policy interventions may generate immediate or delayed effects 12 , with direct effects being easier to detect and visualize. When the impact of the intervention is delayed over time, we should justify the difference between the policy change and its expected effects.

\section{Computational tools}

The data was analyzed using R Statistical 3.6.3 (http://www.r-project.org), and all significance tests were two-sided. Replication materials, including raw data and computational scripts, are available at: https://osf.io/ns3k6/.

\section{Results}

Figure 1 shows the epidemic curves for COVID-19 cases and deaths in four Brazilian capitals over time. Figure 2 compares the expected number of daily cases and deaths and the respective actual values of registered COVID-19 occurrences in each city, with the light blue interval indicating the duration of the intervention.

Before the policy change, the trend was positive and statistically significant for all units (Table 2). Controlling for prior trend, we observed statistically significant decreases in São Luís $\left(\beta_{3}=-0.09\right.$; $\mathrm{p}$-value $<0.001)$, Recife $\left(\beta_{3}=-0.12\right.$; $\mathrm{p}$-value $\left.<0.001\right)$, Belém $\left(\beta_{3}=-0.13\right.$; $\mathrm{p}$-value $\left.<0.001\right)$, and Fortaleza $\left(\beta_{3}=-0.07 ; \mathrm{p}\right.$-value $\left.<0.001\right)$ (Table 2$)$.

The mortality trend before the intervention was also positive for all cities, meaning an increasing number of deaths over time, showing a statistically significant slope change after lockdown. All coefficients for the post-intervention period were negative, as hypothesized: São Luís $\left(\beta_{3}=-0.13\right.$; p-value $<0.001)$, Recife $\left(\beta_{3}=-0.06\right.$; $\mathrm{p}$-value $\left.<0.001\right)$, Belém $\left(\beta_{3}=-0.10\right.$; $\mathrm{p}$-value $\left.<0.001\right)$ and Fortaleza $\left(\beta_{3}=-0.09 ; \mathrm{p}\right.$-value $\left.<0.001\right)$ (Table 3).

To acquire more robust estimates, we re-run all regression models using a 15 to 21 days window time frame (Figure 3 ) and observed the following pattern: $\beta_{3}$, the coefficient indicating the trend of the post-intervention period, remained negative and statistically significant for all cities and all periods.

Finally, we estimated the average difference in daily deaths in the absence of the lockdown. In São Luís, we observed a reduction of $37.85 \%$ while in Fortaleza the decrease was $33.4 \%$, on average. Similarly, the lockdown reduced mortality in Recife by $21.76 \%$ and Belém had $16.77 \%$ fewer deaths than would be expected without stricter social distance measures. 


\section{Figure 1}

COVID-19 epidemic curves for total cases and deaths in four Brazilian capitals.

1a) São Luís

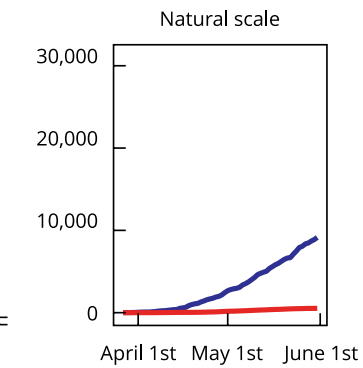

1c) Belém

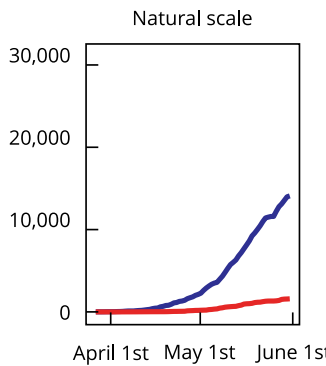

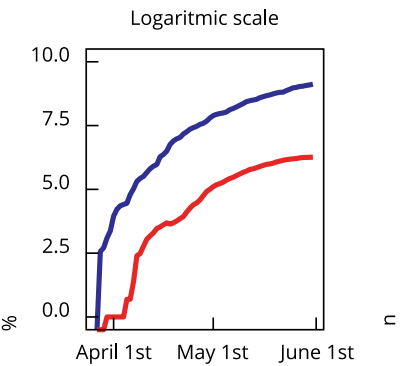
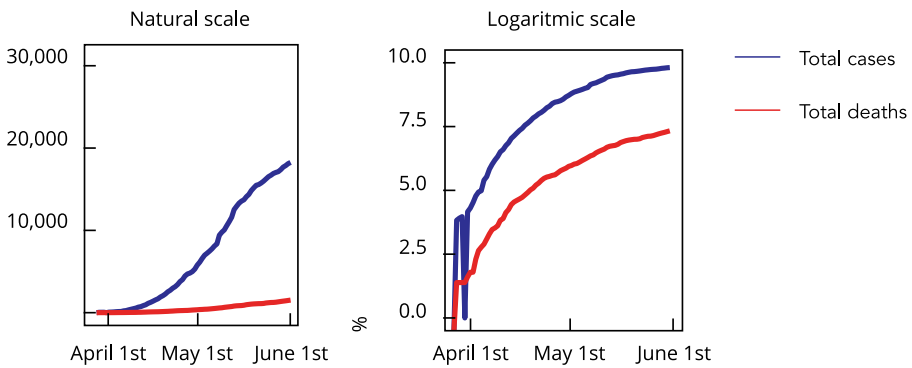

1d) Fortaleza
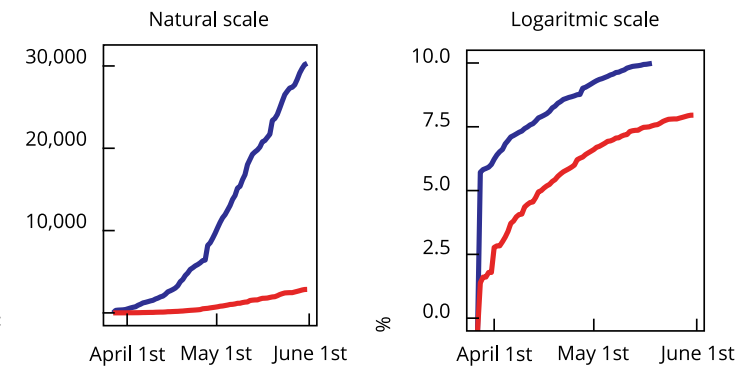

Figure 2

Interrupted time series (ITS) for new daily cases and deaths in four Brazilian capitals.

2a) New daily cases
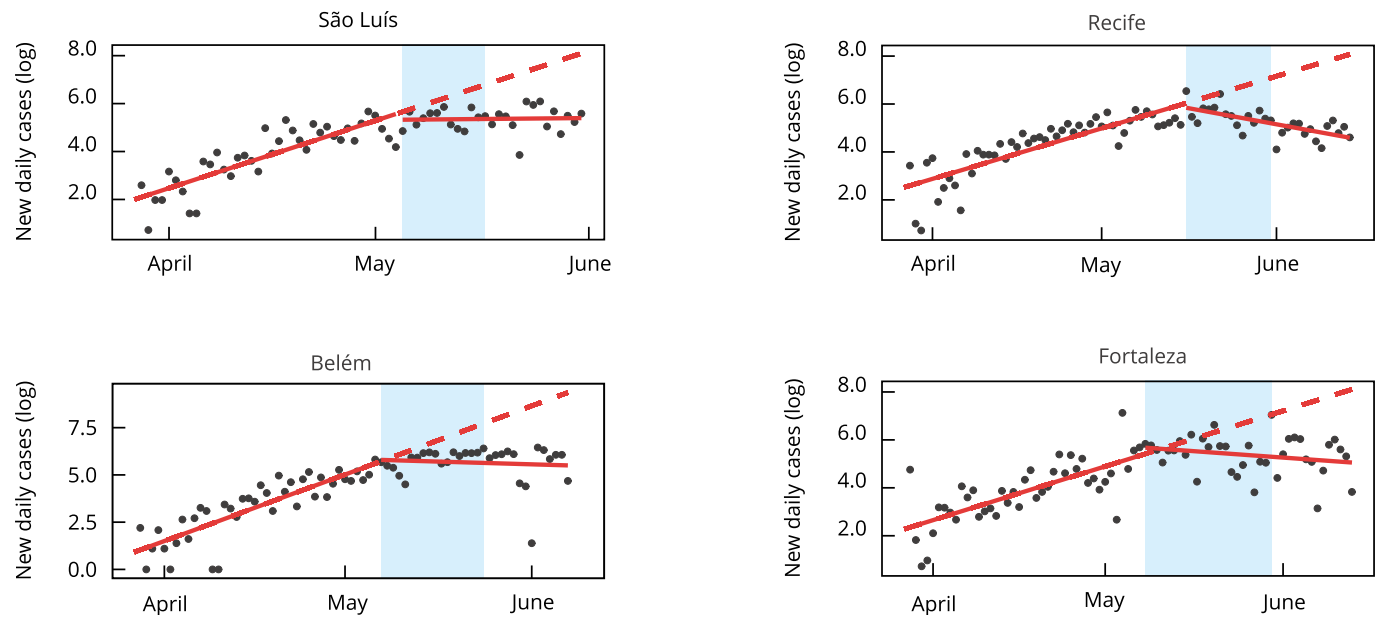

(continues) 
Figure 2 (continued)

2b) Deaths
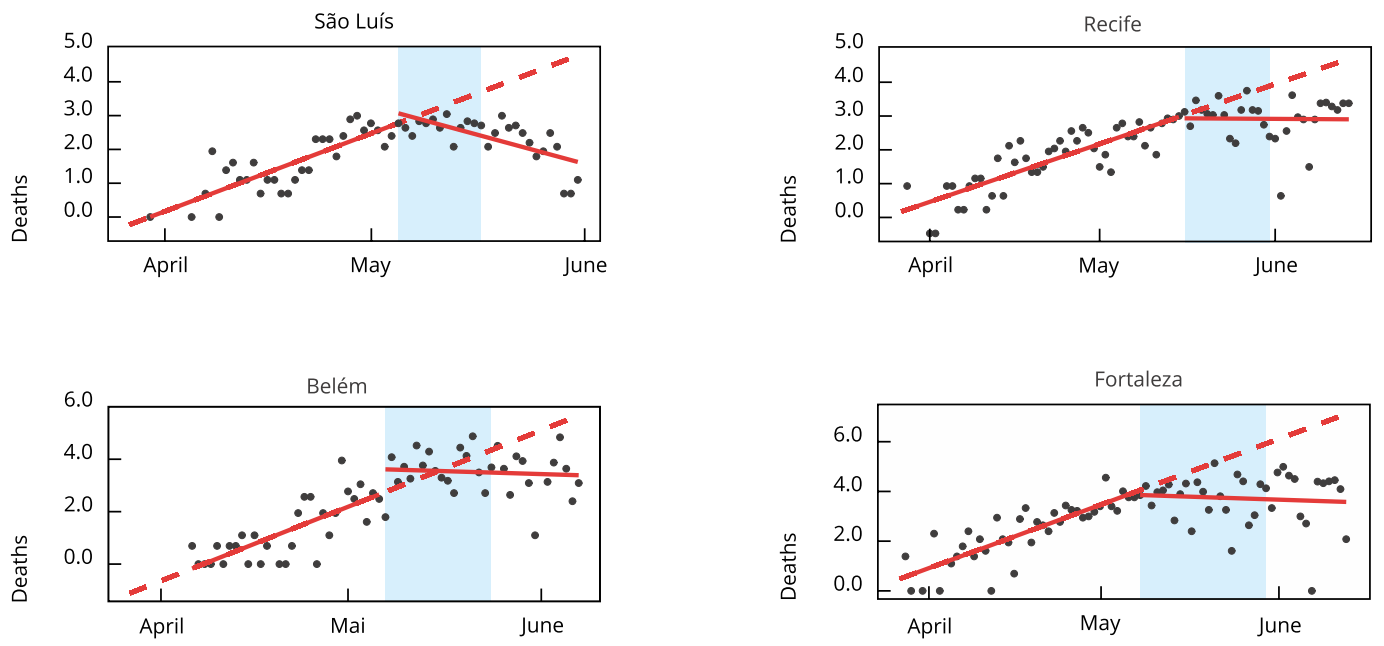

Table 2

Interrupted time series (ITS) model for new daily cases (14 days observation period after lockdown ended).

\begin{tabular}{|c|c|c|c|c|}
\hline & $\begin{array}{l}\text { São Luís (Maranhão State) } \\
\qquad \begin{array}{c}\text { [n }=65] \\
\alpha(S E)\end{array}\end{array}$ & $\begin{array}{l}\text { Recife (Pernambuco State) } \\
\qquad \begin{array}{c}{[n=79]} \\
\alpha(S E)\end{array}\end{array}$ & $\begin{array}{l}\text { Belém (Pará State) } \\
\qquad \begin{array}{c}{[n=72]} \\
\alpha(S E)\end{array}\end{array}$ & $\begin{array}{l}\text { Fortaleza (Ceará State) } \\
\qquad \begin{array}{c}{[n=78]} \\
\alpha(\mathrm{SE})\end{array}\end{array}$ \\
\hline Intercept & $1.88 *(0.21)$ & $2.85 *(0.18)$ & $0.80 * *(0.31)$ & $3.81 *(0.21)$ \\
\hline Time & $0.09 *(0.01)$ & $0.07 *(0.01)$ & $0.12 *(0.01)$ & $0.06 *(0.01)$ \\
\hline Level & $-0.24(0.31)$ & $-0.08(0.28)$ & $0.20(0.45)$ & $0.26(0.29)$ \\
\hline Trend & $-0.09 *(0.02)$ & $-0.11 *(0.01)$ & $-0.13 *(0.02)$ & $-0.07 *(0.01)$ \\
\hline $\mathrm{R}^{2}$ & 0.77 & 0.72 & 0.74 & 0.59 \\
\hline
\end{tabular}

SE: standard error.

* $p<0.001$;

** $p<0.05$.

Table 3

Interrupted time series (ITS) model for new daily deaths (14 days observation period after lockdown ended).

\begin{tabular}{|c|c|c|c|c|}
\hline & $\begin{array}{l}\text { São Luís (Maranhão State) } \\
\qquad \begin{array}{c}\text { [n }=57] \\
\beta(\mathrm{SE})\end{array}\end{array}$ & $\begin{array}{l}\text { Recife (Pernambuco State) } \\
\qquad \begin{array}{c}{[n=75]} \\
\beta(S E)\end{array}\end{array}$ & $\begin{array}{l}\text { Belém (Pará State) } \\
\qquad \begin{array}{c}{[n=61]} \\
\beta(S E)\end{array}\end{array}$ & $\begin{array}{l}\text { Fortaleza (Ceará State) } \\
\qquad \begin{array}{c}{[n=75]} \\
\beta(S E)\end{array}\end{array}$ \\
\hline Intercept & $-0.30(0.26)$ & $0.58 *(0.20)$ & $-1.21 * *(0.46)$ & $0.40(0.32)$ \\
\hline Time & $0.08 * * *(0.01)$ & $0.06 * * *(0.01)$ & $0.09 * * *(0.02)$ & $0.08 * * *(0.01)$ \\
\hline Level & $0.42(0.26)$ & $-0.04(0.27)$ & $0.97 * \star(0.42)$ & $-0.10(0.40)$ \\
\hline Trend & $-0.13 * * \star(0.02)$ & $-0.06 * * *(0.01)$ & $-0.10 * * *(0.02)$ & $-0.09 * * *(0.02)$ \\
\hline $\mathrm{R}^{2}$ & 0.68 & 0.69 & 0.72 & 0.56 \\
\hline
\end{tabular}

SE: standard error.

* $p<0.01$;

** $p<0.05$;

$\star \star * p<0.001$. 


\section{Figure 3}

Interrupted time series (ITS) models using a 15 to 21 days window time frame for new daily cases and newdeaths.

3a) New daily cases
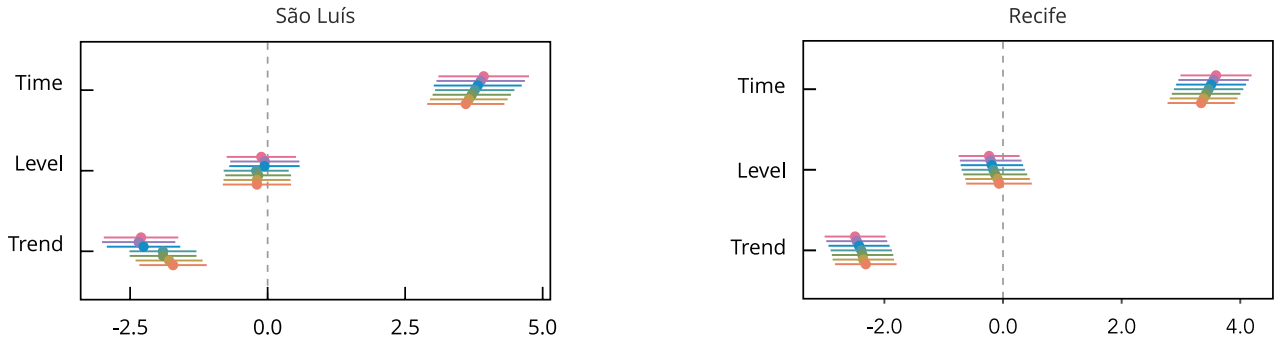

Days post-intervention
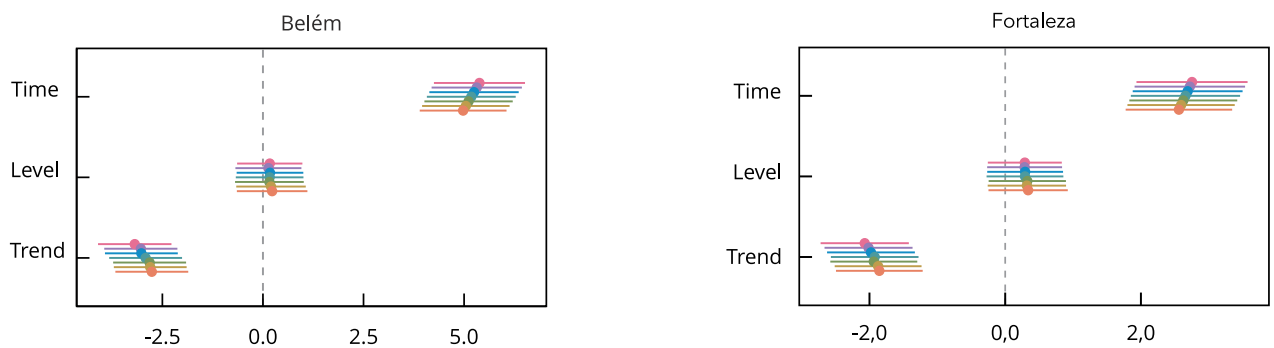

15

16

17

- 18

- 19

- 20

- 21

3b) Deaths
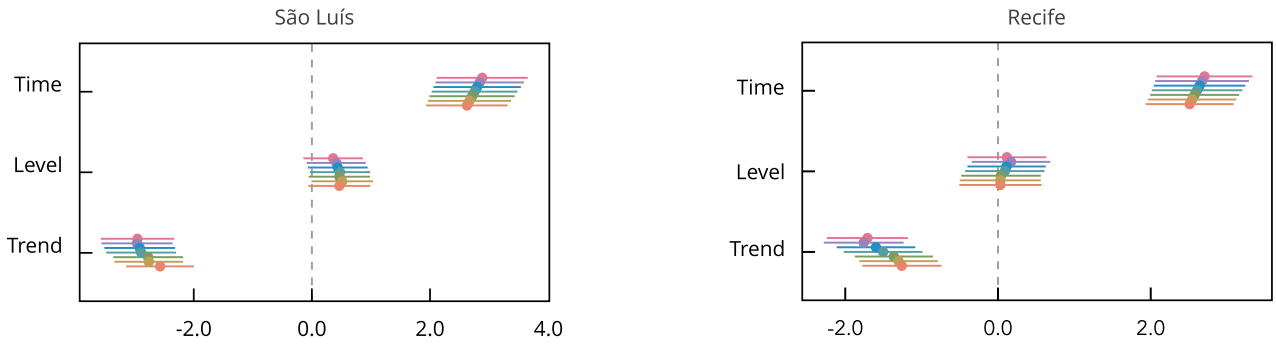

Days post-intervention

15

16

- 17

- 18

19

20
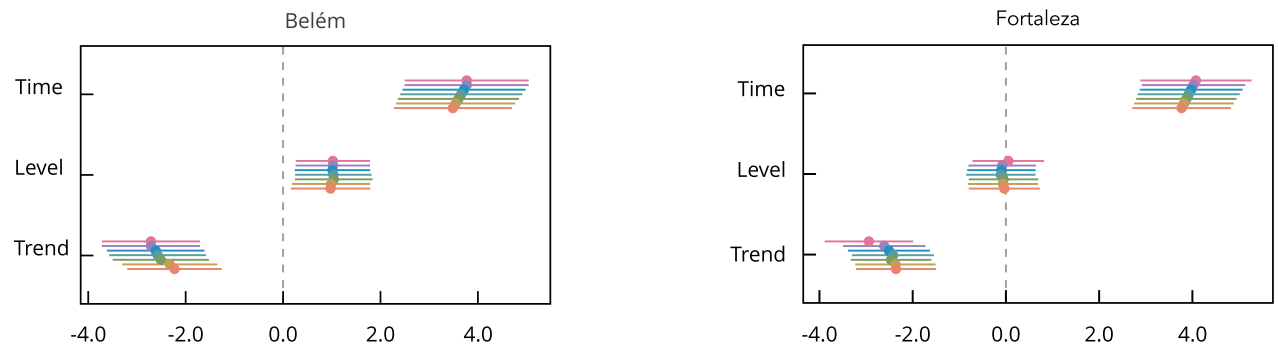

21 


\section{Discussion}

Social distance is a well-established non-pharmaceutical intervention that aims to reduce the spread of infectious diseases 18 . Studies using ITS design consistently reports significant effects of social distancing policies on the SARS-CoV-2 epidemic.

In an experimental study involving 149 countries, Islan et al. 19 found that enforcing any social distance measure reduced in 13\% the incidence of COVID-19 (IRR = 0.87; 95\%CI: 0.85-0.89). Regarding lockdown, the authors state that the rapid implementation of these measures promotes an even more significant reduction (pooled IRR $=0.86$; 95\%CI: 0.84-0.89; $\mathrm{n}=105$ ) compared with a delayed implementation.

Figueiredo et al. 20 estimated the impact of lockdown policies on COVID-19 incidence and mortality in China, which reported a daily reduction of $6.43 \%$ in the number of cases and of $7.88 \%$ in registered deaths. Molefi et al. 4 identified a $47 \%$ decrease in daily cases comparing the pre and postintervention periods.

Siedner et al. 21 , also employing ITS to evaluate the effect of social distancing policies in the United States, found a statistically significant daily decrease of $0.8 \%$ on mean state-level COVID-19 epidemic growth. Ghanbari et al. 22 assessed the impact of lockdown policies on SARS-CoV-2 in Iran, and the results indicate an average decrease of 288.57 on new confirmed cases and 24.67 deaths after the policy intervention.

Evaluating how lockdown policies affected the spread of the SARS-CoV-2 epidemic in Spain and Italy, Tobías 23 reports that the first lockdown reduced incidence in both countries, though the trends remained positive. After the second and stricter lockdown, the slope of the number of case incidence changed and became negative. Still in Europe, Vokó \& Pitter 7 found an average reduction of $0.9 \%$ in the incidence of COVID-19 in 28 countries.

Using original data, we provide evidence of how lockdown interventions affected the SARS-CoV-2 epidemic in Brazil. We found that the initial number of new cases and new deaths had a positive trend before the policy change, showing a statistically significant decrease in new confirmed cases in all state capitals after lockdown. We also found evidence that lockdown measures were likely to reverse the trend of daily deaths due to COVID-19.

We identified three main limitations. First, Brazilian official data shows some inconsistencies that may affect estimates efficiency; thus, studies working with small samples could fail to reject the null hypothesis due to micronumerosity. Second, testing intensified during the post-intervention period, resulting in a higher number of diagnosed cases that can lead to underestimating policy change impact. Finally, there is significant delay between testing cases and actual report them in official datasets, which are likely to introduce both random and systematic measurement errors in statistical estimates. 


\section{Contributors}

L. Silva and D. Figueiredo Filho participated in the conception and design, data interpretation, statistical analysis and writing the manuscript. A. Fernandes contributed in the analysis, writing and revision of the manuscript.

\section{Additional informations}

ORCID: Lucas Silva (0000-0002-5013-6278); Dalson Figueiredo Filho (0000-0001-6982-2262); Antônio Fernandes (0000-0002-0249-517X).

\section{Acknowledgments}

To Rafael Mesquita (Federal University of Pernambuco - UFPE), Bruna Alquete (Pernambuco State Department of Planning and Management - SEPLAG-PE), Gabriela Morais (State University of Health Sciences of Alagoas - UNCISAL), and Leonardo Barichello (Campinas State University UNICAMP) for their useful comments that helped improve the contents of the manuscript.

\section{References}

1. Ferrante L, Fearnside PM. Protect Indigenous peoples from COVID-19. Science 2020; 368:251.

2. COVID-19 in Brazil: "so what?". Lancet 2020; 395:1461.

3. Cornwall W. Can you put a price on COVID-19 options? Experts weigh lives versus economics. Science 200; 31 mar. https://www. sciencemag.org/news/2020/03/modelersweigh-value-lives-and-lockdown-costs-putprice-covid-19.

4. Molefi M, Tlhakanelo J, Phologolo T, Hamda SG, Masupe T, Tsima B, et al. The impact of China's lockdown policy on the incidence of CoVID-19: an interrupted time series analysis. Research Square 2020; 2 jun. https://www.researchsquare.com/article/rs-32944/v1.

5. Sarwal R, Sarwal T. Mitigating COVID-19 with lockdowns: a possible exit strategy. SSRN 2020; 29 mar. https://ssrn.com/abs tract $=3563538$.

6. Vokó Z, Pitter JG. The effect of social distance measures on COVID-19 epidemics in Europe: an interrupted time series analysis. GeroScience 2020; 42:1075-82.

7. Calderon-Anyosa RJ, Kaufman JS. Impact of COVID-19 lockdown policy on homicide, suicide, and motor vehicle deaths in Peru. medRxiv 2020; 14 jul. https://www.medrxiv. org/content/10.1101/2020.07.11.20150193v1.

8. World Health Organization. Considerations for quarantine of individuals in the context of containment for coronavirus disease (COVID-19). Geneva: World Health Organization; 2020.

9. Lauer SA, Grantz KH, Bi Q, Jones FK, Zheng $\mathrm{Q}$, Meredith HR, et al. The incubation period of coronavirus disease 2019 (COVID-19) from publicly reported confirmed cases: estimation and application. Ann Intern Med 2020; 172:577-82.

10. Lee H, Kim K, Choi K, Hong S, Son H, Ryua S. Incubation period of the coronavirus disease 2019 (COVID-19) in Busan, South Korea. J Infect Chemother 2020; 26:1011-3.

11. Zaki N, Mohamed E. The estimations of the COVID-19 incubation period: a systematic review of the literature. medRxiv 2020; 14 jul. https://www.medrxiv.org/content/10.1101/ 2020.05.20.20108340v2.

12. Shadish WR, Cook TD, Campbell DT. Experimental and quasi-experimental designs for generalized causal inference. Boston: Houghton Mifflin; 2002.

13. Bernal JL, Cummins S, Gasparrini A. Interrupted time series regression for the evaluation of public health interventions: a tutorial. Int J Epidemiol 2017; 46:348-55.

14. Wagner AK, Soumerai SB, Zhang F, Ross-Degnan D. Segmented regression analysis of interrupted time series studies in medication use research. J Clin Pharm Ther 2002; 27:299-309. 
15. Biglan A, Ary D, Wagenaar AC. The value of interrupted time-series experiments for community intervention research. Prev Sci 2000; 1:31-49.

16. Hudson J, Fielding S, Ramsay CR. Methodology and reporting characteristics of studies using interrupted time series design in healthcare. BMC Med Res Methodol 2019; 19:137.

17. Kontopantelis E, Springate DA, Ashworth M, Webb RT, Buchan IE, Doran T. Investigating the relationship between quality of primary care and premature mortality in England: a spatial whole-population study. BMJ 2015; 350:h904.

18. Alfano V, Ercolano S. The efficacy of lockdown against COVID-19: a cross-country panel analysis. Appl Health Econ Health Policy 2020; 18:509-17.

19. Islam N, Chowell G, Shabnam S, Kawachi I, Lacey B, Massaro JM, et al. Physical distancing interventions and incidence of coronavirus disease 2019: natural experiment in 149 countries. BMJ 2020; 370:m2743.
20. Figueiredo AM, Codina AD, Figueiredo D, Saez M, León AC. Impact of lockdown on COVID-19 incidence and mortality in China: an interrupted time series study. Bull World Health Organ 2020; [Epub ahead of print].

21. Siedner MJ, Harling G, Reynolds Z, Gilbert RF, Haneuse S, Venkataramani A, et al. Social distancing to slow the U.S. COVID-19 epidemic: an interrupted time-series analysis. medRxiv 2020; 20 jun. https://www.medrxiv.org/conte $\mathrm{nt} / 10.1101 / 2020.04 .03 .20052373 \mathrm{v} 3$.

22. Ghanbari MK, Behzadifar M, Imani-Nasab MH, Behzadifar M, Bakhtiari A, Mir I, et al. The impact of the social distancing policy on COVID-19 new cases in Iran: insights from an interrupted time series analysis. Research Saquare 2020; 28 apr. https://www.researchsquare.com/article/rs-25818/v1.

23. Tobías A. Evaluation of the lockdowns for the SARS-CoV-2 epidemic in Italy and Spain after one month follow up. Sci Total Environ 2020; 725:138539. 


\section{Resumo}

Em resposta à pandemia da COVID-19, muitos governos no mundo adotaram políticas de distanciamento social, com diferentes níveis de implementação e adesão. Realizamos uma análise de séries temporárias interrompidas para estimar o impacto dos lockdowns na redução do número de casos e óbitos por COVID-19 no Brasil. Os dados diários oficiais foram coletados para quatro capitais estaduais, antes e depois das respectivas intervenções politicas, com base em uma janela de 14 dias de observação. Estimamos uma regressão linear segmentada para avaliar a efetividade das medidas de lockdown sobre a incidência e mortalidade de COVID-19. O número inicial de novos casos e óbitos mostrou uma tendência positiva antes da mudança política. Depois do lockdown, foi observada uma queda estatisticamente significativa em novos casos confirmados, em todas as capitais. De maneira semelhante, as evidências mostraram que medidas de distanciamento revertiam a tendência de novos óbitos diários pela COVID-19. Em São Luís, observamos uma redução de 37,85\%, enquanto em Fortaleza a queda foi de 33,4\% na diferença média em óbitos diários, comparado com uma eventual não implementação de lockdown. Além disso, a intervenção diminuiu a mortalidade em Recife em 21,76\%, e em Belém em 16,77\%. As politicas de distanciamento social podem ser ferramentas úteis no achatamento da curva epidêmica.

SARS-CoV-2; COVID-19; Distância Social; Séries Temporais Interrompidas

\section{Resumen}

En respuesta a la pandemia de COVID-19, muchos gobiernos en todo el mundo han implementado las politicas de distanciamiento social con diferentes niveles, tanto en lo que se refiere a la observancia, como al cumplimiento. Realizamos un análisis de serie temporal interrumpida para estimar el impacto de los confinamientos en reducir el número de casos y muertes, debidos a la COVID-19 en Brasil. Los datos oficiales diarios fueron recogidos de cuatro capitales antes y después de sus respectivas politicas de intervención, basadas en el mantenimiento de 14 días de observación de autoconfinamiento. Estimamos una regresión lineal segmentada para evaluar la efectividad de las medidas de confinamiento en la incidencia de COVID-19 y la mortalidad. El número inicial de nuevos casos y nuevas muertes tuvo una tendencia positiva previa al cambio de política. Tras el confinamiento, se presentó una disminución estadísticamente significativa de nuevos casos confirmados, que fueron encontrados en todas las capitales de estado. De igual modo, encontramos evidencias de que las medidas de confinamiento probablemente revirtieron la tendencia de nuevas muertes diarias debidas al COVID-19. En São Luís, observamos la reducción de un 37,85\%, mientras en Fortaleza la disminución fue de un $33,4 \%$ en la diferencia media en muertes diarias, si no se hubiera implementado el confinamiento. Igualmente, la intervención redujo la mortalidad en Recife en un 21,76\% y Belém tuvo un 16,77\%. Las políticas de distanciamiento social pueden ser herramientas útiles en el aplanamiento de la curva epidémica.

SARG-CoV-2; COVID-19; Distancia Social; Series de Tiempo Interrumpido

Submitted on $21 / \mathrm{Jul} / 2020$

Final version resubmitted on 27/Aug/2020

Approved on 31/Aug/2020 